\title{
Friction Factors Determination of the Auxiliary Ventilation System in an Underground Mine
}

\author{
Marc Bascompta $^{1}$, Lluís Sanmiquel ${ }^{1}$, José Juan de Felipe ${ }^{2}$, Jordi Vives ${ }^{2}$ \\ ${ }^{1}$ ICL Chair in Sustainable Mining, Polytechnic University of Catalonia (UPC) \\ Avenue Bases de Manresa, 61-73, 08242-Manresa (Barcelona) \\ marc.bascompta@upc.edu; lluis.sanmiquel@upc.edu \\ ${ }^{2}$ Department of Mining Engineering, Industrial and ICT, Polytechnic University of Catalonia (UPC) \\ Avenue Bases de Manresa, 61-73, 08242-Manresa (Barcelona) \\ jordi.vives@upc.edu; jose.juan.de.felipe@upc.edu
}

\section{Extended Abstract}

The determination of the friction factor in the auxiliary ventilation system of a mine is crucial in terms of efficiency and health and safety of the employees. While the main ventilation system of a mine is usually well defined and modelled, the auxiliary system still presents some setbacks due to each mine has its specific features and changes along the mine life.

The air passing throw the faces is usually done by means of flexible ducts. The advantage of this system is the easiness of installing it or modify it. However, it does not resist well undesired impacts from the equipment or rock falling. The quantity of these impacts is a function of the extraction method and create an amount of leakages that are not considered in the duct features provided by the manufacturer. Nevertheless, it changes the maximum length of the duct and therefore, the maximum workface length for each ventilation configuration.

This study used a case study to define a methodology and find the equivalent friction factors due to the real conditions of a mine. These new values are validated with real data and the auxiliary ventilation system is modelled to predict the workface conditions in terms of airflow.

Keywords: Friction factor, Underground mining, Ventilation. 